\title{
El microrrelato: polémica de las definiciones
}

Nada Mohamad Salaheddin Hasan Mustafa Elsaady

\author{
Ayudante de profesor, \\ Facultad de Al-Alsun, \\ Universidad de Al-Minia, \\ Minia, \\ Egypt
}

\begin{abstract}
Resumen
El trabajo plantea diversidad terminológica del género del microrrelato que resulta la falta de consenso entre los especialistas del género a la hora de determinar una denominación única de él a través de limitar los criterios que controlan su denominación. El trabajo tiene como propósito presentar la denominación más exacta del género y excluir las fórmulas que no se pueden considerar como : "microrrelato". Extrae desde dicha polémica de denominaciones por parte de los especialistas del género, una estrategia integral de la denominación del género, agrupando las ideas de dicha estrategia y presentarlas como un método que se puede seguir para determinar la denominación más exacta del género, dependiendo de las opniones de los especialistas en este respecto. El trabajo demuestra también otras propuestas de denominaciones del género por otros especialistas que dependen en los criterios de la extensión y la difusión del género como base para denominarlo.
\end{abstract}

\section{Palabras claves}

Microrrelato-Denominaciones-Polémica

\begin{abstract}
This paper presents the variety of terms of the micro-story genre that results in the lack of consensus among gender specialists when determining a unique denomination of it through limiting the criteria that control its denomination. The purpose of this study is to present the most accurate name of this gender and exclude formulas that cannot be considered as "micro- story". It extracts from this controversy of denominations, made by the specialists of this narrative gender, an integral strategy of the denomination of the gender, grouping the ideas of said strategy and presenting them as a method that can be followed to determine the most exact denomination of the gender, depending on the opinions of specialists in this regard. The work also demonstrates other suggestions for gender denominations by other specialists who depend on the criteria of the extension and diffusion of the gender as the basis for naming it.
\end{abstract}

\section{Keywords}

Micro- story-Denominations-Controversy

\section{Introducción}

El microrrelato es una construcción narrativa distinta de la novela y del cuento, que se caracteriza esencialmente por ser tan breve, y, por lo tanto, más complejo. Cabe destacar que hay muchos escritores importantes en el mundo hispánico que escribieron ciertas series de notables microrrelatos durante las últimas décadas, como Augusto Monterroso, Julio Cortázar, Jorge Luis Borges, Juan José 
Arreola y Julio Torri, quien se podría considerar como uno de los precursores del género. Asimismo, los siguieron posteriormente grandes autores como; Ana María Matute, Max Aub, Adolfo Bioy Casares y Eduardo Galeano con una producción amplia de considerables minicuentos.

La minificción llama la atención de cualquier investigador que busca todo lo nuevo, interesante y rico en el campo literario, así que este tema vuelve a ser en los últimos años el objetivo del estudio y de la crítica por parte de muchos críticos y estudiosos. Por otro lado, los lectores españoles e hispanoamericanos se inclinan, en estos días, a explorar el mundo del microrrelato, tanto pasado, como actual, lo cual hace que dicho género se extienda cada día más.

En este estudio vamos a abordar el planteamiento de la controversia que estalló entre los especialistas del género a la hora de denominar a esa modalidad narrativa novedosa.

\section{Polémica de las denominaciones del microrrelato}

A pesar del número creciente de los estudios realizados en las últimas décadas por los especialistas de la minificción, que analizan la cuestión preliminar de la nomenclatura del género, este asunto se considera aún un tema de debate. Los especialistas del género no tuvieron la misma opinión ni el mismo canon a la hora de poner nombre a estos textos breves, lo cual genera muchos problemas relacionados tanto con la delimitación del corpus exacto del género como la determinación de las características diferenciales del mismo, algo que abrió la puerta de cierta subjetividad en la lectura y en el análisis por los receptores, pero fue, simultáneamente, un motivo que ayudó asimismo a impulsar a los investigadores para llenar este vacío teórico.

La falta de acuerdo sobre su denominación estimuló la creación de nuevos términos y la consolidación de los ya existentes. La mayoría de estos factores responden a criterios literarios, aunque no faltan otros relacionados con factores no literarios. En cuanto a los criterios literarios de los que derivan la mayoría de las denominaciones de estas construcciones breves son: la extensión, la ficcionalidad, la procedencia genérica y la narratividad.

Así, aparte de algunas denominaciones que sólo reflejan la brevedad del género como: "texto breve" o "texto brevísimo", se aplican términos que aluden tanto a su brevedad como a su condición ficcional como; "minificción", "microficción" y "ficción brevísima". Igualmente, hay expresiones en las que aparecen la referencia a la extensión del género, con su relación genealógica respecto al cuento, y su discurso narrativo implícito, como: "cuento breve", "brevicuento", "cuento cortísimo", "cuento diminuto", "cuento en miniatura", "minicuento", "cuento mínimo" y "microrrelato". Otras denominaciones resaltan aspectos relacionados de manera especial con su recepción; "cuento instantáneo", "ficción de un minuto", "ficción rápida" o "ficción súbita".

La precisión de la elección y de la utilización de unos u otros términos es una cuestión importante. Ya que su empleo, dependiendo de los detalles más específicos de los vocablos combinados de cada denominación, está estrechamente relacionado con la ampliación o reducción del corpus del género; así como la consideración de cuáles son en realidad sus rasgos canónicos. 
En su libro La era de la brevedad, Irene Andres- Suárez propone una división de las denominaciones más tratadas del género, donde agrupa en dos bloques esenciales, claramente diferenciados, los términos más empleados. El bloque primero contiene los términos; "microrrelato", "minirrelato", "microcuento" y "minicuento". Andres- Suárez dice que se pueden tomar a todas dichas denominaciones como sinónimos ya que designan al texto articulado en torno a los principios básicos de brevedad, narratividad y calidad literaria en prosa. Por otro lado, el segundo grupo consta de la denominación: "minificción" (igual a "microficción" o "ficción mínima") que designan, según sus palabras:

Una supercategoría literaria poligenérica, es decir, un hiperónimo que agrupa a los microtextos literarios en prosa, tanto a los narrativos como a los no narrativos. En suma, todo "microrrelato" es una "minificción", pero no toda "minificción" ha de ser un "microrrelato".

\section{Método de Lagmanovich: hacia una denominación precisa del género}

El especialista del género de la minificción, David Lagmanovich, crea cierta técnica de gran importancia para tratar la cuestión de la diversidad terminológica del género. A continuación, se detalla su planteamiento que nosotros podríamos considerar como un método integral que llamamos: "Método de Lagmanovich", dedicándolo este apartado del trabajo, ya que, sus principios básicos se consideran tan decisivos e imprescindibles en este estudio de las denominaciones del género.

En su libro El microrrelato: teoría e historia, Lagmanovich establece cuatro categorías para tratar esta cuestión, empieza su examen de la terminología del género con el concepto de "texto". Pues, él percibe el mundo como un inmenso conjunto de textos que produce constantemente la actividad humana. Tanto los mensajes gestuales, las piezas musicales, las pinturas, los documentos escritos como los mensajes orales todos estos son meros textos ${ }^{2}$.El autor los clasifica en "textos verbales" y "textos no verbales". Él aclara que los verbales se caracterizan por el uso del lenguaje y se separan, a su vez, en orales y escritos ${ }^{3}$.

En este mismo orden, Lagmanovich sigue su tratamiento de los rasgos del microrrelato, refiriéndose al segundo rasgo: la literariedad. Dice que los textos verbales escritos se dividen, por su parte, en literarios y no literarios. Y distingue entre ambos por un ejemplo que lo aclara diciendo que La descripción de la topografía de una provincia española no es habitualmente un texto literario, pero, por otro lado, un poema de Campos de castilla, de Antonio Machado, por ejemplo, indudablemente lo es. Para tal propósito, él precisa la definición de la "literalidad" diciendo que es: "Un producto de ciertas características estructurales y de ciertos rasgos que transmiten el significado, todo esto aceptado en virtud de condiciones

\footnotetext{
${ }^{1}$ Andres-Suárez y A. Reivas, la era de la brevedad; el microrrelato hispánico, Palencia, España, 2008, Pág. 16

${ }^{2}$ David Lagmanovich, El microrrelato. Teoría e historia, Palencia, Menoscuarto, 2006, pág.20

${ }^{3}$ Ibídem, págs. 20 y 21
} 
estéticas que el lector reconoce como tales"4. Por lo tanto, se puede decir que todos los textos verbales escritos en cualquier lenguaje que obtienen el rasgo de la literalidad crean una clase de índole especial y se catalogan dentro de un solo nombre; "la literatura", según él ${ }^{5}$.

En este respecto, es necesario señalar que los textos que se caracterizan por ser breves, pero no son literarios, o bien, en otras palabras; " no ficcionales", no se deben considerar como microrrelatos, sino; "microtextos". Tomando como ejemplos de éstos: los anuncios publicitarios en una transmisión televisiva, los grafitis, las noticias y los breves comentarios encontrados en los periódicos. Pues, si bien, muchos de estos textos son de alto nivel de creatividad, no se puede incluirse dentro de la categoría del género del microrrelato. La razón de eso es que una noticia periodística se organiza por lo común sobre un esquema narrativo, pero está básicamente arraigada en la realidad y no en la ficción: "Muestra, o se supone que muestre, lo que es, no lo que puede ser" 6 .

El tercer rasgo predominante del género --después de la ""verbalidad" y la "literariedad"-- es la "narratividad". En este respecto, Lagmanovich aclara que todo microrrelato debe contener una situación básica que se narra, un incidente capaz de introducir un cambio en la situación inicial y, por último, un desenlace o un final que a veces, vuelve a la situación inicial Asimismo, él asegura la importancia de la narratividad como característica capital del género: "Cuando un microtexto es ficcional, y cuando la consiguiente minificción es esencialmente narrativa, estamos en presencia de un microrrelato"7.

Según Lagmanovich, la cuarta característica definidora del género después de las ya tratadas es la "brevedad" , que se considera la más importante. Esta cualidad tiene un carácter especial, ya que se diferencia de las otras características por ser un rasgo difícil de especificar y, al mismo tiempo, imprescindible en tal tratamiento por ser el más definidor de este género de textos hiperbreves. El problema de la complejidad de la determinación precisa de los límites de dicha cualidad deriva de que, la "brevedad" en sí es un término relativo. Los textos considerados "breves" por algunos, se pueden considerar como "largos" por otros. Algo que detallaremos más adelante. Al final, queremos asegurar que esta propuesta recién tratada por Lagmanovich se completa recíprocamente con la de Irene Andrés-Suárez anteriormente planteada.

\section{Consideraciones sobre el método de Lagmanovich}

Pretendiendo llegar a determinar las denominaciones más aceptables y exactas del género, Lagmanovich empleó cierto método integrado y tuvo éxito en reducir los rasgos específicos de este género a través de incluir solamente las características singulares que se ajustan a la naturaleza excepcional de este género, y así, omitir todos los términos que no se cuadran con él ${ }^{8}$.

\footnotetext{
${ }^{4}$ Ibídem, pág. 20

${ }^{5}$ Ibídem, pág. 21

${ }^{6}$ Ibídem, pág.23

${ }^{7}$ Ibídem, pág.26

${ }^{8}$ Ibídem, Págs.23:28.
} 


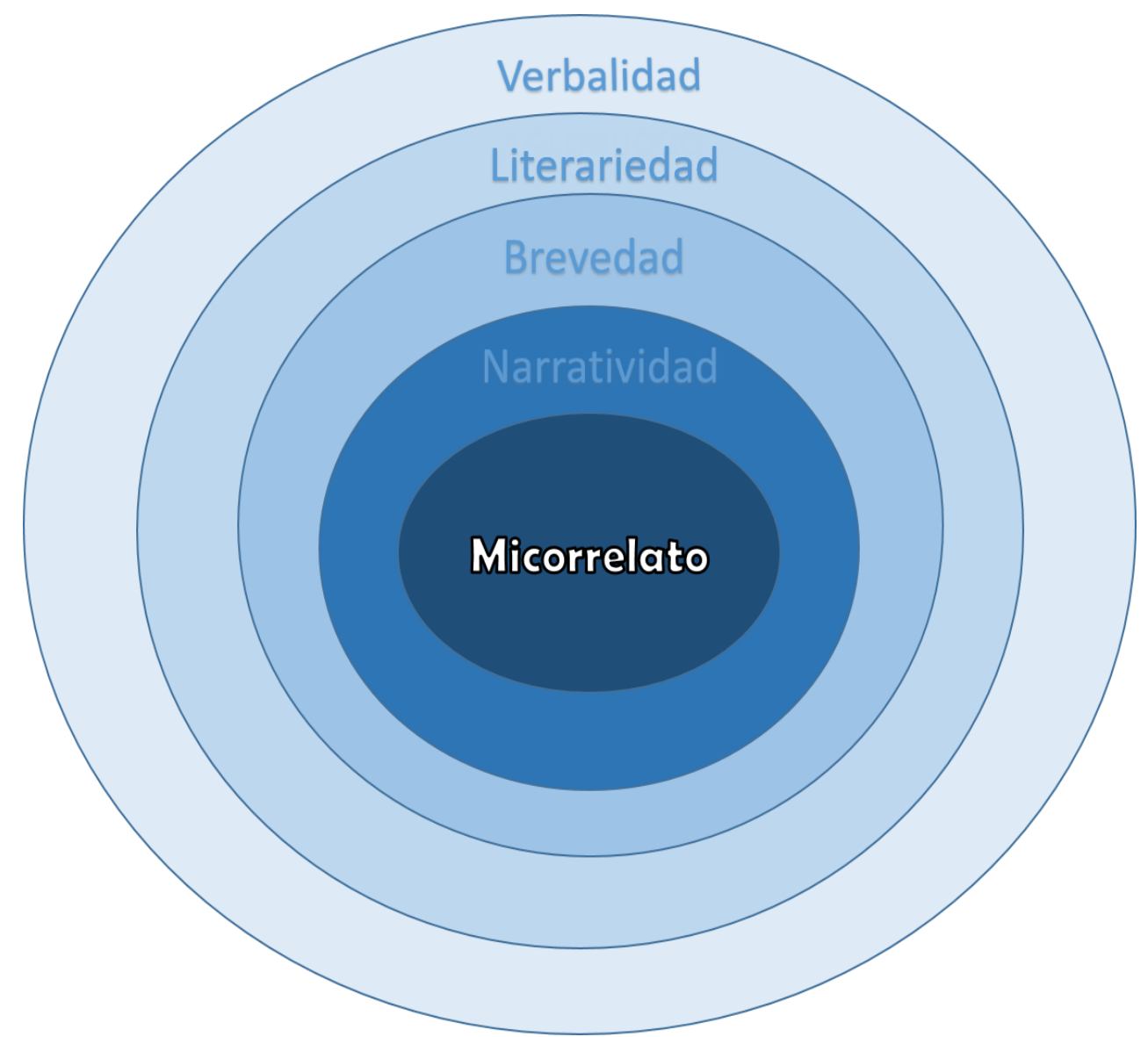

Ilustración 1 Los círculos concéntricos de Lagmanovich

Explicando la idea de esta ilustración queremos aludir a que imaginamos el método de Lagmanovich como algo parecido a unos círculos concéntricos como los indicados en la figura anterior. Para saber si un texto pertenece a la clase de microrrelato o no, debe lograr pasar por estos cuatro pasos de refinamiento del microrrelato. Dichos niveles reflejan las características definidoras del microrrelato, es decir, las condiciones esenciales que lo forman.

A través de pasar descendentemente en dicha clasificación de dichos círculos concéntricos, se podría lograr la determinación exacta de la nomenclatura del género y concretar la definición del microrrelato basándose en dichos rasgos. En consecuencia, el género del microrrelato incluye ya cualquier texto que cumpla los condicionantes de ser verbales, breves, literarios y narrativos. Por lo tanto, cualquier forma parecida al microrrelato, si carece de una o más de estas condiciones de dichos círculos, no se puede incluir dentro de la categoría de este género, lo cual se podría aclarar en la siguiente tabla. 
Tabla 1 Ejemplos ajenos al microrrelato según los rasgos definidores puestos por Lagmaonvich

\begin{tabular}{|l|l|l|l|}
\hline $\begin{array}{l}\text { Características } \\
\text { Definidoras }\end{array}$ & \multicolumn{2}{|l|}{ Ejemplos Excluyentes } \\
\hline Verbalidad & Películas & Anuncios & Pinturas \\
\hline Literariedad & $\begin{array}{l}\text { Notas de } \\
\text { prensa }\end{array}$ & $\begin{array}{l}\text { Anuncias por } \\
\text { palabras }\end{array}$ & $\begin{array}{l}\text { Textos } \\
\text { instruccionales }\end{array}$ \\
\hline Brevedad & Novelas & $\begin{array}{l}\text { Mircotextos de la } \\
\text { representación } \\
\text { teatral }\end{array}$ & Épicas \\
\hline Narratividad & Poemas &
\end{tabular}

Del planteamiento anterior se podría llegar a cierta conclusión clave. Dependiendo de este método, Lagmanovich opina que el "microrrelato" es la denominación más aceptada que las otras denominaciones del género, ya que cumple todas las condiciones que incluye a todas las características del género que marcan su denominación y optamos por esta opinión. Cabe aludir que optamos por este punto de vista de denominar al género y creemos que es el término más integral que los otros que contiene todos los elementos que forman a este género, basando en este método.

\section{La brevedad como criterio de la denominación del género}

El principio clave y el más controvertido en el que se basan casi todos los especialistas a la hora de determinar las denominaciones más apropiadas es la "brevedad". Por eso, nos parece imprescindible tratarlo con más detalles. En primer lugar, cabe reiterar que el concepto de lo que es breve y lo que no lo es se considera como algo relativo que depende de otros factores contextuales que se ven afectados por el ámbito geográfico, cultural, lingüístico y, ciertamente, histórico. Por eso, la nomenclatura, según la extensión, encuentra dificultades para fijar los límites que se toman como referencia. A pesar de eso hay ciertos investigadores que tuvieron éxito haciendo una clasificación de los nombres del microrrelato. La siguiente tabla muestra cierta escala de denominaciones según el número de palabras o páginas propuestas por los críticos: Lauro Zavala ${ }^{9}$, por parte de la crítica hispana; y Robert Shapard ${ }^{10}$ y Fernández Beschtedt ${ }^{11}$, por parte de la anglosajona:

\footnotetext{
${ }^{9}$ Lauro Zavala, Cartografías del cuento y la minificción, Sevilla, Renacimiento, 2004, págs. $86: 98$

${ }^{10}$ Robert Shapard, "Panorama de la situación de la minificción en los EE. UU., Micro, Flash y Súbita", El cuento en red 19, primavera 2009, disponible en línea, http://cuentoenred.xoc.uam.mx/busqueda.php

${ }^{11}$ Mercedes Fernández Beschtedt,"Como el pan nuestro de cada día: El microrrelato en su versión anglosajona", El cuento en red 15, primavera 2007, disponible en línea: http://cuentoenred.xoc.uam.mx/
} 
Tabla 2 Denominaciones según la extensión.

\begin{tabular}{|c|c|c|}
\hline Autor & Denominación propuesta & Número de palabras \\
\hline $\begin{array}{l}\text { Fernández } \\
\text { Beschtedt }\end{array}$ & $\begin{array}{ll}\text { - } & \text { Short Story } \\
\text { - } & \text { Sudden Fiction Flash } \\
\text { - } & \text { Fiction Microfiction } \\
\text { - } & \text { Drabble } \\
\text { - } & \text { Nanofiction }\end{array}$ & $\begin{array}{ll}\text { - } & \begin{array}{l}\text { Entre } 2000 \text { y } 20000 \\
\text { palabras. }\end{array} \\
\text { - } & \begin{array}{l}\text { Entre } 1000 \text { y } 2000 \\
\text { palabras. }\end{array} \\
\text { - } & \begin{array}{l}\text { Menos de } \quad 1000 \\
\text { palabras }\end{array} \\
\text { - } & \begin{array}{l}\text { Alrededor de } \quad 300 \\
\text { palabras. }\end{array} \\
\text { - } & \begin{array}{l}\text { Exactamente } \\
\text { palabras } 55 \text { palabras } \\
\text { o menos }\end{array} \\
\end{array}$ \\
\hline Lauro Zavala & $\begin{array}{l}\text { - } \text { Cuento corto } \\
\text { - Muy corto } \\
\text { - Ultracorto }\end{array}$ & 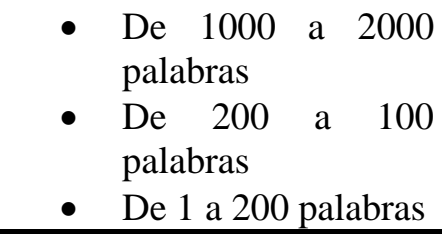 \\
\hline Robert Shapard & $\begin{array}{ll}\text { - } & \text { Micro } \\
\text { - } & \text { Flash } \\
\text { - } & \text { Súbita. }\end{array}$ & $\begin{array}{ll}\text { - } & \text { Hasta media página } \\
\text { - } & \text { Dos páginas } \\
\text { - } & \text { Hasta cuatro } \\
& \text { páginas }\end{array}$ \\
\hline
\end{tabular}

En la anterior clasificación de nombres de microrrelatos según la extensión, se podría considerar que la cartografía de Fernández Beschtedt es la más integral, ya que está realizada de manera bien escalonada, que abarca el mayor número posible de las extensiones desde sólo una palabra hasta veinte mil. Al contrario, la división propuesta por Zavala no tiene la misma precisión, ya que deja ambigua la titulación de ciertas extensiones, como aquellas que giran alrededor de 300 a 1000 palabras. Por último, la técnica de Robert Shapard de medir por páginas y no palabras, implica un criterio que pueda ser más adecuado con el carácter estético de estas obras de literatura. Ya que, él no pretende ser tan minucioso en contar el número de palabras de forma tan matemática, como si fuera una tierra de cultivo, sino que propone medirlo de una forma aproximada. Pero, al otro lado, este método no puede llegar a la exactitud absoluta porque no tomó en consideración las características de la página como el tamaño de los márgenes ni el de las letras.

Aunque la extensión breve es una característica tan básica de los microrrelatos, siendo el pilar de los rasgos que definen a este género de textos, Lagmanovich aclara que basarse tan sólo en dicha brevedad no sería un criterio tan válido para definir a estos textos, porque es un rasgo no bien definido y relativo. Es que el tamaño es una característica que se podría cambiar de una etapa, de una cultura, de un país a otros. Lagmanovich dice: "Hoy encontramos larguísimas ciertas obras literarias que, probablemente, en su siglo no llamaban la atención por su extensión: "la Divina comedia, de Dante Alighieri, o el paraíso perdido, de John 
Milton, por ejemplo"12 .También, la idea de la brevedad varía según la recepción por los lectores, es decir, según las expectativas variables desde una sociedad a otra. Un ejemplo relevante de eso se advierte en la cultura anglosajona, en ésta se ven titulados como minicuentos "short short stories" a los mismos que en el mundo hispánico son considerados como cuentos normales, aunque ambos obtienen la misma extensión, medida en el número de páginas y de palabras.

Al final, hay que subrayar que existe otra denominación destacada entre todos los términos que dependen de la extensión; es el término "hiperbreve". Esta denominación, si bien se basa en la misma idea de la brevedad, se considera un caso diferente. Es que, este término consiguió gran difusión especialmente en España gracias a la publicación de ciertas antologías del género, sobre todo, las promovidas por el Círculo Cultural Faroni, cuyos títulos lo conllevan dicho término como: Quince líneas. Relatos hiperbreves y Galería de hiperbreves: Nuevos relatos mínimos. La especialista del microrrelato Clara Obligado también lo utilizó en su publicación: Porfavor, sea breve. Antología de relatos hiperbreves.

\section{Conclusión}

Desde dicha falta de consenso planteada en este trabajo en cuanto a denominar al género, se puede decir que estas modalidades narrativas expuestas en este trabajo de investigación: el "microrrelato"; tiene más que una denominación, entre los cuales se destacan, el microrrelato, el minicuento, la minificción, hiperbreve y cuento corto. Cabe destacar que las primeras cuatro denominaciones son los más famosos tanto entre los especialistas del género como entre los lectores del mismo.

Podemos concluir diciendo que la estrategia, que ha seguido el especialista Lagmanovich para determinar la denominación más exacta del género, es la más integral de las demás propuestas de las denominaciones. Ya que, las otras opiniones sólo se basan en unos ciertos criterios del género, como la extensión y la difusión del mismo, y hacen caso omiso de otras características tan importantes que lo define al género. Dicha estrategia se considera la más aceptada porque es la más integral que agrupa a casi todos los criterios que limitan las características básicas de este género: la verbalidad, la literariedad, la narratividad y la brevedad. Podemos decir que las ideas de esta propuesta se pueden considerar como método fundamental que se pueda seguir para determinar la denominación más precisa del género.

Dependiendo de este método, optamos por la opinión que establece que la denominación el "microrrelato" es la más aceptada y la más integral que las otras denominaciones del género, ya que cumple todas las condiciones que envuelven las características básicas de estos textos según esta estrategia. Así que, el género del microrrelato incluye ya cualquier texto que cumpla los condicionantes de ser verbales, breves, narrativos y literarios. Por lo tanto, cualquier forma parecida al

${ }^{12}$ David Lagmanovich, El microrrelato.Teoría e Historia, Palencia, Menoscuarto, 2006, p.22. 
microrrelato, si carece de una o más de estas condiciones, no se puede incluir dentro de la categoría de este género.

Por otro lado, la polémica de la denominación del género hace subrayar también el término: "minificción", que se considera como un hiperónimo que agrupa los microtextos literarios en prosa; tanto los narrativos como los no narrativos. Se puede decir ya que todo "microrrelato" es una "minificción", pero no toda "minificción" ha de ser un "microrrelato", según la especialista Irene Andres-Suárez.

Al final, destaca también las opiniones de los investigadores Lauro Zavala Robert Shapard y Fernández Beschtedt, que han dependido tan sólo en el criterio de la extensión breve del género para denominarlo. Es decir, han trazado unas denominaciones según el número de palabras o páginas del texto. Concluyendo diciendo que optamos por la clasificación de Fernández Beschtedt, en este cuanto, por ser la más integral que las tres propuestas, ya que abarca el mayor número posible de las extensiones del microrrelato, desde sólo una palabra hasta veinte mil.

\section{Bibliografía}

Andres-Suárez, \& Reivas, A. (2008). la era de la brevedad; el microrrelato hispánico. Palencia, España.

Lagmanovich و David, El microrrelato. Teoría e historia, Palencia, Menoscuarto, 2006, p. 20

Mercedes Fernández Beschtedt,"Como el pan nuestro de cada día: El microrrelato en su versión anglosajona", El cuento en red 15, primavera 2007, disponible en línea: http://cuentoenred.xoc.uam.mx/, 24-9-2019

Obligado, Clara, (ed.), Por favor, sea breve. Antología de relatos hiperbreves, Madrid, Páginas de Espuma, 2001.

Shapard, Robert , "Panorama de la situación de la minificción en los EE. UU., Micro, Flash y Súbita", El cuento en red 19, primavera 2009, disponible en línea, http://cuentoenred.xoc.uam.mx/busqueda.php, 2-4-2019

Zavala, Lauro, Cartografías del cuento y la minificción, Sevilla, Renacimiento, 2004, págs. 86:98. 